\title{
Lupus Vulgaris: A Rare Case of Cutaneous Tuberculosis
}

MA Chowdhury ${ }^{1}$, TK Sikdar ${ }^{2}$

\begin{abstract}
:
Lupus vulgaris is an extremely chronic, progressive form of cutaneous tuberculosis. The earliest description of lupus vulgaris was given by Erasmus Wilson in 1865. It usually occurs through contagious extension of the disease from underlying affected tissue or hematogenous or lymphatic spread. A 55 years male, non diabetic, non hypertensive, non smoker, got himself admitted into Dermatology and Venereology Department of DMCH with the complaints of multiple ulcerated lesions over the left lower thigh and upper leg including knee for 8 years. Histological sections of skin revealed multiple epithelioid granuloma, multinucleated giant cells and infiltration of lymphocytes with areas of fibrosis and ESR was 80 in 1st hour. The patient was treated with anti tubercular therapy and cured completely.
\end{abstract}

Key words: Lupus Vulgaris, Cutaneous tuberculosis, Epithelioid granuloma, Anti-TB therapy.

\section{Introduction:}

Cutaneous tuberculosis makes up a small proportion of extrapulmonary tuberculosis. Studies from South East Asia report an incidence of $0.1 \%$ of all cases of extra pulmonary tuberculosis. ${ }^{1}$ It takes different clinical forms depending on patient's immune status. ${ }^{2}$ Lupus vulgaris is the most common type of cutaneous tuberculosis, with most varied manifestations. ${ }^{3}$ It is a chronic and progressive form occurring in individuals with high degree of tuberculin sensitivity and moderate immunity. A characteristic feature of lupus vulgaris is its extremely chronic course with slow but steady growth of the lesions over a period of many years, even decades. Head and neck are the sites commonly affected in European countries. Here we report a case of lupus vulgaris with extensive involvement of very large sized, multiple plaques occurring at unusual sites.

\section{Case Report:}

A 55 years old male from Araihazar Upazilla of Narayangong District, attended in Skin \& VD Department of Dhaka Medical College Hospital, presented with the complaints of multiple ulcerated lesions over the left lower

1. Dr. Chowdhury Mohammad Ali, Professor \& Head, Department of Skin \& VD, Dhaka Medical College, Dhaka.

2. Dr. Tushar Kanti Sikdar, Assistant Professor, Department of Skin \& VD, Dhaka Medical College, Dhaka.

\section{Corresponding Author:}

Dr. Chowdhury Mohammad Ali

Professor \& Head, Department of Skin \& VD, Dhaka himself admitted into Skin \& VD Department of DMCH. On inspection a hyperpigmented, well-marginated plaque type lesion with multiple different sized ulcers over the left lower thigh \& upper leg including knee, one of the ulcers was large and others were small. At the periphery of ulcers there were a few papules and nodules, margin of the large ulcer was sharply defined forming a serpiginous border, base of the ulcer was covered with brownish thick crust, some areas showed reddish granulation tissue, atrophy and scarring. On palpation, lesions were mildly tender, local temperature was not raised. Diascopic examination of the papules and nodules revealed the Apple-jelly appearance. On laboratory findings, ESR was 80 in First hour, X- ray chest revealed no abnormality, no AFB was found in sputum, tuberculin test was negative and histopathological findings showed multiple epithelioid granuloma, multinucleated giant cells and infiltration of lymphocytes with areas of fibrosis. The patient was treated with anti TB drugs for six months and cured.

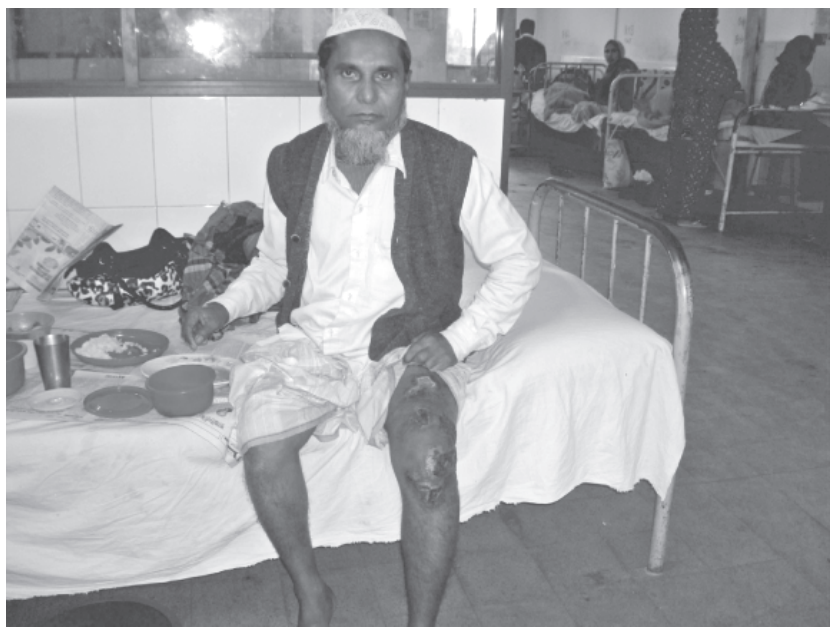

Photograph of the Patient

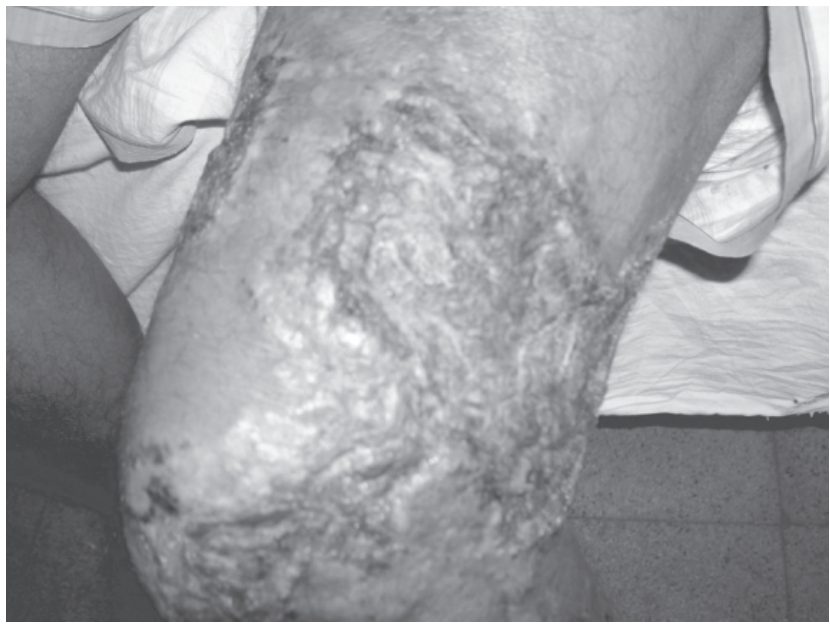

Before Treatment 


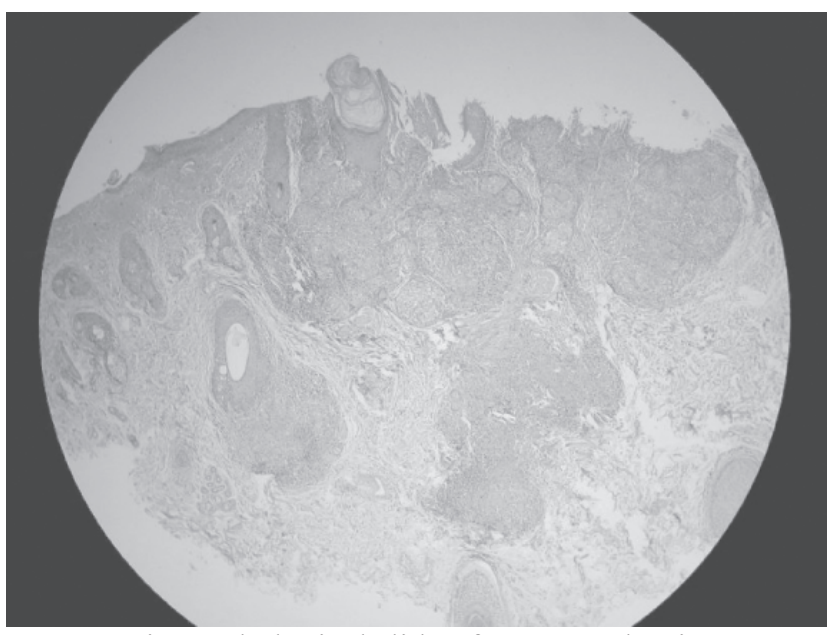

Histopathological slide of Lupus Vulgaris

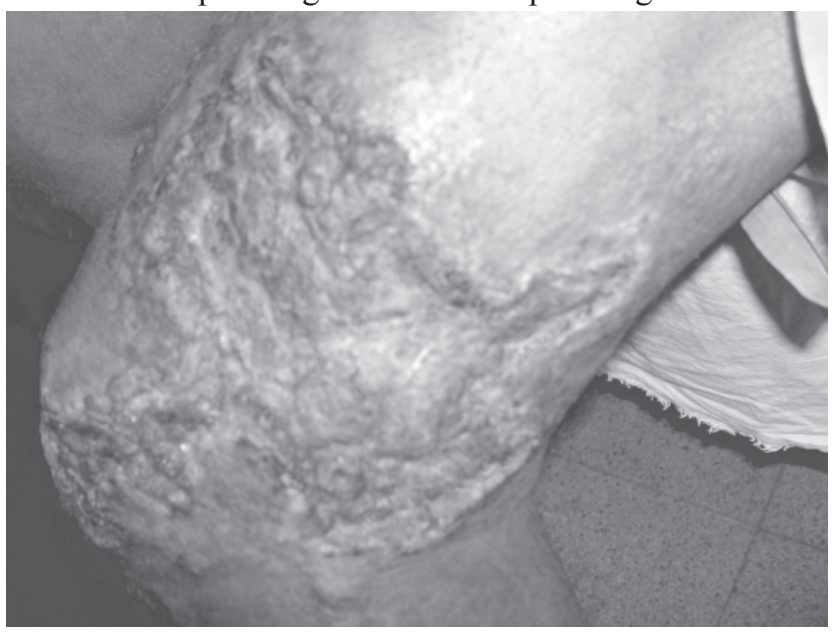

After 2 months Of therapy

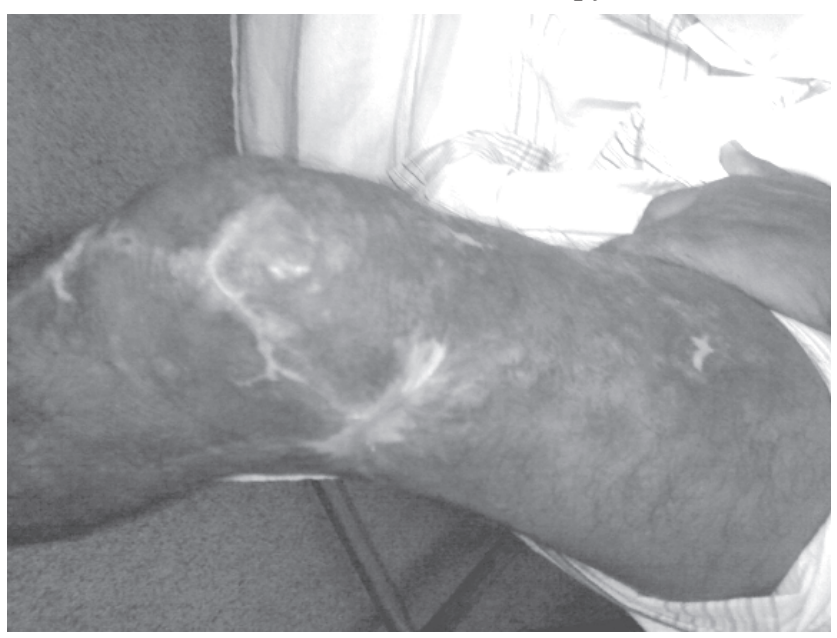

After 06 months of therapy

\section{Discussion:}

Lupus vulgaris is an extremely chronic, progressive form of cutaneous tuberculosis. The earliest description of lupus vulgaris was given by Erasmus Wilson in $1865 .{ }^{4}$ It usually occurs through contiguous extension of the disease from underlying affected tissue or hematogenous or lymphatic spread. ${ }^{5}$ It can also arise after exogenous inoculation or as a complication of BCG vaccination. ${ }^{6}$ Breach in the

\section{Discussion:}

Lupus vulgaris is an extremely chronic, progressive form of cutaneous tuberculosis. The earliest description of lupus vulgaris was given by Erasmus Wilson in $1865 .{ }^{4}$ It usually occurs through contiguous extension of the disease from underlying affected tissue or hematogenous or lymphatic spread. ${ }^{5}$ It can also arise after exogenous inoculation or as a complication of BCG vaccination. ${ }^{6}$ Breach in the integrity of the skin can serve as a portal of entry for the AFB.The initial lesion is a small, reddish-brown papule or nodule which later forms larger plaques by peripheral enlargement and coalescence that show evidence of healing and scarring in one area and activity in another. 7,8 Atrophic scarring, with or without ulceration, is a prominent feature of lupus vulgaris. ${ }^{5}$ Histopathology showed tuberculoid granulomas composed of lymphocytes, plasma cells, epitheloid cells and giant cells, scant or absent central caseation, in the superficial dermis. The epidermis is usually hyperplastic, but may be atrophic or ulcerated. Tubercle bacilli are difficult to demonstrate. ${ }^{3}$

\section{Conclusion:}

Cutaneous tuberculosis makes up a small proportion of extrapulmonary tuberculosis. Studies from South East Asia reported an incidence of $0.1 \%$ of all cases of extra pulmonary tuberculosis.In this reported case the patient had extensive involvement of very large sized, multiple plaques occurring at unusual sites which was confirmed by histopathological study and 6(six) months Anti-TB therapy is also sufficient enough for the treatment of such type of case.

1. Sehgal VN, Wagh SA. Cutaneous tuberculosis. Int J Dermatol 1990;29:237-52.

2. Jain VK, Aggaral K, Jain S, Singh S. Hypertrophic lupus vulgaris: An unusual presentation. Indian J Dermatol 2009;54:287-9.

3. Valia RG, Valia AR, editors. IADVL Textbook of Dermatology. 3 rd ed, vol 1. Mumbai, India: Bhalani Publishing House; 2008. p. 245-6.

4. Findlay GH. Bacterial infections. In: Findlay GH, editors. The Dermatology of Bacterial infections. 1 st ed. London: Blackwell Scientific; 1987. p. 71-83.

5. Burns T, Breathnach S, Cox N, Griffiths C, editors. Rook's Textbook of Dermatology. 8 th ed. West Sussex (UK): Wiley-Blackwell Publications; 2010. p.

6. Kanwar AJ. Lupus vulgaris following BCG vaccination. Int J Dermatol 1988;27:525-6.

7. Kumar B, Muralidhar S. Cutaneous tuberculosis- A 20 year prospective study. Int. J Tuberc Lung Dis 1999;3:494-500.

8. Singhal A, Sonthalia S. Cutaneous tuberculosis in children: The Indian perspective. Indian J. Dermatol Venerol Leprol 2010;76:494-503. 